\title{
On-Demand Therapy with Proton Pump Inhibitors for Maintenance Treatment of Nonerosive Reflux Disease or Mild Erosive Esophagitis: A Systematic Review and Meta-Analysis
}

\author{
Zubair Khan $\left(\mathbb{D},{ }^{1}\right.$ Yaseen Alastal, ${ }^{1}$ Muhammad Ali Khan $\left(\mathbb{D},{ }^{2}\right.$ Mohammad Saud Khan $\left(\mathbb{D},{ }^{1}\right.$ \\ Basmah Khalil, ${ }^{1}$ Shreesh Shrestha, ${ }^{2}$ Faisal Kamal, ${ }^{2}$ Ali Nawras, ${ }^{1}$ and Colin W. Howden ${ }^{2}$ \\ ${ }^{1}$ Division of Gastroenterology and Hepatology, University of Toledo Medical Center, Toledo, OH, USA \\ ${ }^{2}$ Division of Gastroenterology and Hepatology, The University of Tennessee Health Science Center, Memphis, TN, USA \\ Correspondence should be addressed to Muhammad Ali Khan; mkhan24@uthsc.edu
}

Received 20 February 2018; Revised 30 June 2018; Accepted 10 July 2018; Published 12 August 2018

Academic Editor: Paolo Gionchetti

Copyright (C) 2018 Zubair Khan et al. This is an open access article distributed under the Creative Commons Attribution License, which permits unrestricted use, distribution, and reproduction in any medium, provided the original work is properly cited.

Background. Proton pump inhibitors (PPIs) are widely used for the long-term management of gastroesophageal reflux disease (GERD). However, concerns about the cost and/or inconvenience of continuous maintenance PPI treatment have led to the evaluation of various alternative approaches. Aim. To assess the effectiveness of on-demand PPI therapy in the maintenance treatment of nonerosive reflux disease (NERD) or mild erosive esophagitis (EE). Methods. We searched MEDLINE, EMBASE, Web of Science, and Cochrane Library from inception until October 2, 2017, for randomized controlled trials (RCTs) comparing on-demand PPI versus placebo or daily PPI in the management of NERD or mild EE (Savary-Miller grade 1). Discontinuation of therapy during the trial was used as a surrogate for patient dissatisfaction and failure of symptomatic control. We calculated pooled odds ratios (OR) to evaluate the efficacy of on-demand PPI treatment. Separate analyses were conducted for studies comparing on-demand PPI with daily PPI and with placebo. Subgroup analysis was done based on NERD studies alone and on studies of both NERD and mild EE. These were analyzed using a random effects model. Results. We included 10 RCTs with 4574 patients. On-demand PPI was superior to daily PPI (pooled OR =0.50; 95\% confidence interval $(C I)=0.35,0.72)$. On subgroup analysis in NERD patients only, pooled OR was $0.44(0.29,0.66)$. In studies including patients with NERD and mild EE, pooled OR was $0.76(0.36,1.60)$. For studies comparing on-demand PPI with placebo, pooled OR was $0.21(0.15,0.29)$; subgroup analyses of studies evaluating NERD only and studies conducted in NERD and mild EE showed similar results (pooled OR was $0.22(0.13,0.36)$ and $0.18(0.11,0.31)$, resp.). Conclusions. On-demand PPI treatment is effective for many patients with NERD or mild EE. Although not FDA-approved, it may be adequate for those patients whose symptoms are controlled to their satisfaction.

\section{Introduction}

Gastroesophageal reflux disease (GERD) is a common disorder of the upper gastrointestinal tract. The prevalence of reflux symptoms is steadily rising throughout the industrialized world [1]. An estimated $20-40 \%$ of Western adult populations report chronic heartburn or regurgitation symptoms [2]. Different manifestations of GERD include nonerosive reflux disease (NERD) and erosive esophagitis (EE). Complications of GERD, which are generally confined to EE patients, include ulceration, stricture, and Barrett's esophagus with attendant risk of esophageal adenocarcinoma [3]. NERD, the most frequent manifestation of GERD, is present in around $70 \%$ of patients and characterized by the presence of typical GERD symptoms associated with pathological acid reflux but the absence of demonstrable esophageal mucosal injury on endoscopy $[4,5]$. Despite the absence of mucosal injury on endoscopy, many patients with NERD experience severe symptoms and impairment in quality of life that may be equivalent to, or greater than, seen in patients with $\mathrm{EE}$ $[6,7]$. Acid-suppressive therapy with proton pump inhibitors (PPI) has proved to be the most effective treatment strategy 
for both NERD and EE [8-10]. PPIs have shown superiority over histamine $\mathrm{H}_{2}$-receptor antagonists for controlling symptoms as well as for healing erosions and preventing relapse $[8,10]$. However, up to $75 \%$ patients with NERD and up to $90 \%$ of patients with EE may experience symptomatic relapse within six months of stopping treatment $[11,12]$. Therefore, many patients subsequently receive long-term treatment to maintain adequate symptom control and, for EE patients, healing of erosions. However, this may have led to unnecessary use of these drugs, among NERD patients especially, adding to overall costs [13]. In the United States, the total expenditure for PPI treatment may be over $\$ 11$ billion annually [14]. Due to the costs of PPI treatment, there have been efforts to develop effective and cost-efficient alternative long-term maintenance strategies for some GERD patients $[15,16]$, including "on-demand" PPI therapy, with patients taking a daily dose of a PPI when symptoms recur and stopping treatment when symptoms resolve. This is in contrast to intermittent treatment, in which patients take a regular daily dose of a PPI upon symptom relapse and continue it for a prespecified duration (typically 1 or 2 weeks) regardless of symptom response.

To evaluate the effectiveness of on-demand PPI treatment in patients with NERD or mild EE, we conducted a systematic review of randomized controlled trials (RCTs) comparing it with regular daily PPI treatment or placebo.

\section{Methods}

2.1. Data Sources and Search Strategy. We carried out this systematic review and meta-analysis in accordance with the guidelines of preferred reporting items for systematic review and meta-analysis (PRISMA) [17]. The search strategies were developed in Ovid MEDLINE, and the same keywords and subject headings were applied to Ovid EMBASE, Cochrane, Scopus, and ISI Web of Science databases from inception through November 2, 2016. The search terms included "Esophagitis" OR "Gastroesophageal reflux" OR "GERD” OR "Nonerosive reflux disease" OR "NERD” OR "Erosive esophagitis" OR "EE" AND "Proton pump inhibitors" OR "PPIs" AND "on-demand" OR “on demand" OR "daily" AND "Placebo." A medical librarian with more than 20 years of experience performed this search.

2.2. Study Selection and Inclusion and Exclusion Criteria. Two authors (Z.K. and Y.A.) searched for original studies based on the previously defined search strategy. We searched for RCTs comparing on-demand PPI treatment with either placebo or daily PPI in the maintenance treatment of NERD and/or mild EE. NERD was defined as the presence of classic GERD symptoms in the absence of esophageal mucosal injury during upper endoscopy (Savary-Miller Grade 0 and LA class M). Mild EE was defined as having esophagitis with Savary-Miller Grade 1 or LA class A. The main outcome measure used to assess treatment efficacy was discontinuation of therapy during the trial. Continuation of therapy during a trial was used as a surrogate for patient satisfaction and control of GERD symptoms. Hence, the proportion of patients who discontinued therapy during a trial was taken as an indirect measure of failure of symptomatic control of GERD. Studies were excluded if they did not contain raw or usable data or were published only in abstract form. We also excluded duplicate publications, expert opinion, and letters. We also searched bibliographies of retrieved articles to enhance the yield of our search strategy. All articles were downloaded into Endnote 7.0, a bibliographic database manager, and any duplicate citations were identified and removed.

2.3. Data Extraction and Quality Assessment. Two reviewers (Z.K. and Y.A.) assessed the eligibility of selected studies and extracted data using customized data extraction forms. Any disagreement between reviewers was discussed with a third reviewer (M.A.K.), and agreement was reached by consensus. Extracted data included study design, the year and country of publication, inclusion and exclusion criteria, PPI regimen used for on-demand and continuous groups, classification of esophagitis, outcome studied (number of patients discontinuing on-demand treatment due to inadequate symptom control), follow-up duration, and patient demographics.

We used the Cochrane tool for assessing risk of bias for RCTs. Two reviewers (Z.K. and Y.A.) performed quality assessment with any disagreement to be discussed with a third reviewer (M.A.K.). We used the GRADE framework to interpret our findings [18].

2.4. Data Synthesis and Statistical Analysis. Our main outcome of interest was the effectiveness of on-demand PPI treatment versus placebo or daily PPI in the management of NERD and/or mild EE. The primary efficacy endpoint used was the premature discontinuation of treatment. We analyzed pooled data using a random effects model and calculated odds ratios (ORs) with their 95\% confidence interval (CI). We conducted separate analyses for studies comparing on-demand PPI with daily PPI and with placebo. We performed additional subgroup analyses based on NERD studies alone and on studies including patients with either NERD or mild EE. Cochrane's $Q$ test and $I^{2}$ statistics were used to assess heterogeneity among studies. A $P$ value of $<0.1$ for the Cochrane $Q$ test or an $I^{2}$ value of $>50 \%$ signified the presence of heterogeneity.

We constructed funnel plots and used Egger's precision test to assess publication bias. Statistical analysis was performed using RevMan, version 5.3 for Windows (Cochrane Collaboration, the Nordic Cochrane Center, Copenhagen, Denmark, 2014).

\section{Results}

3.1. Search Strategy Yield and Identification of Studies. The search strategy identified 409 articles, of which 35 were removed as duplicates. Of the remaining 374 articles, 347 were removed after title and abstract review. The remaining 27 full-text articles were reviewed, of which 10 RCTs [19-28] with 4574 patients were included in the meta-analysis as shown in PRISMA flowchart (Supplementary Materials (available here)). Among the patients, 2797 received ondemand PPI, 843 received daily PPI and 934 received 


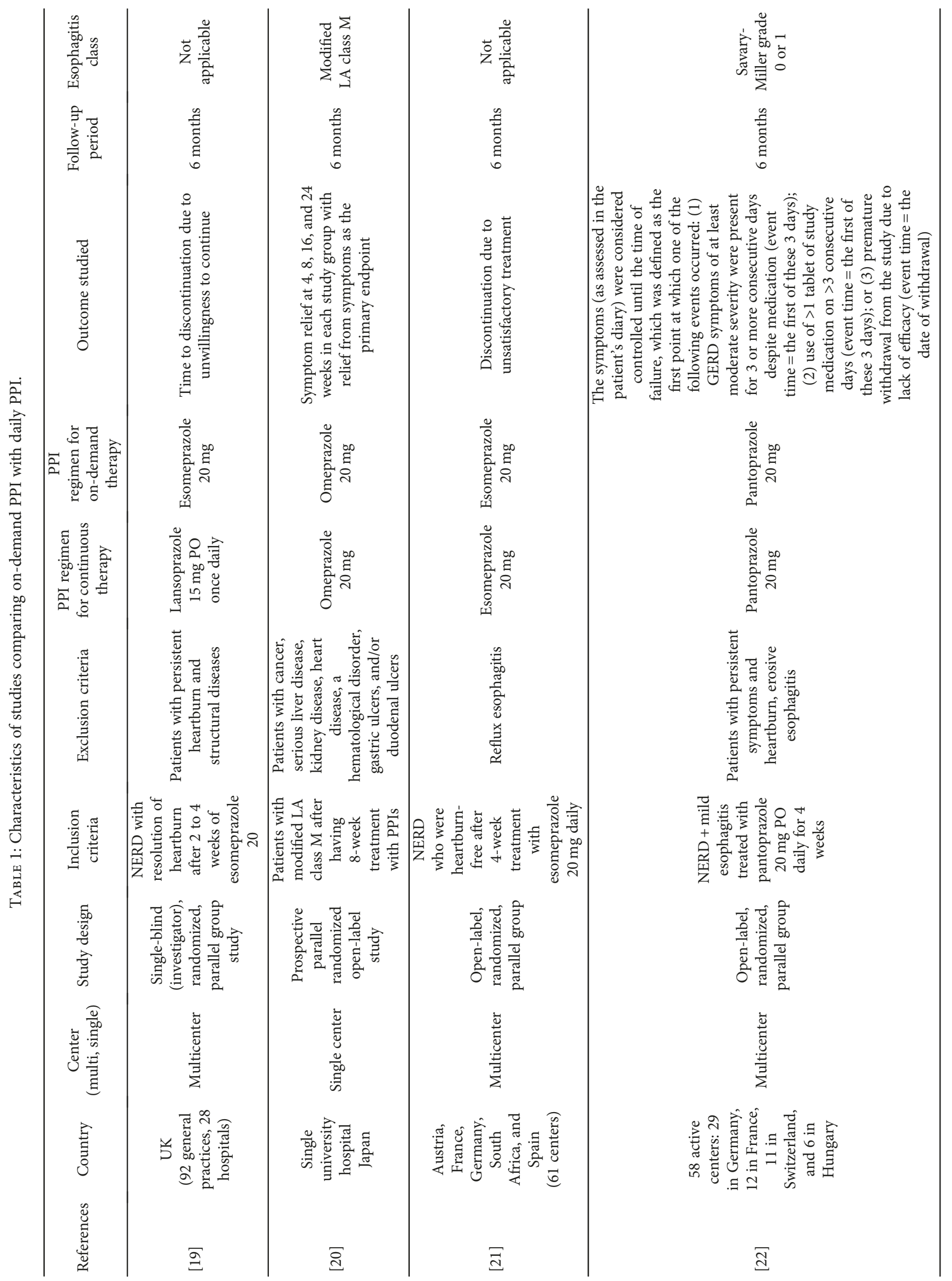




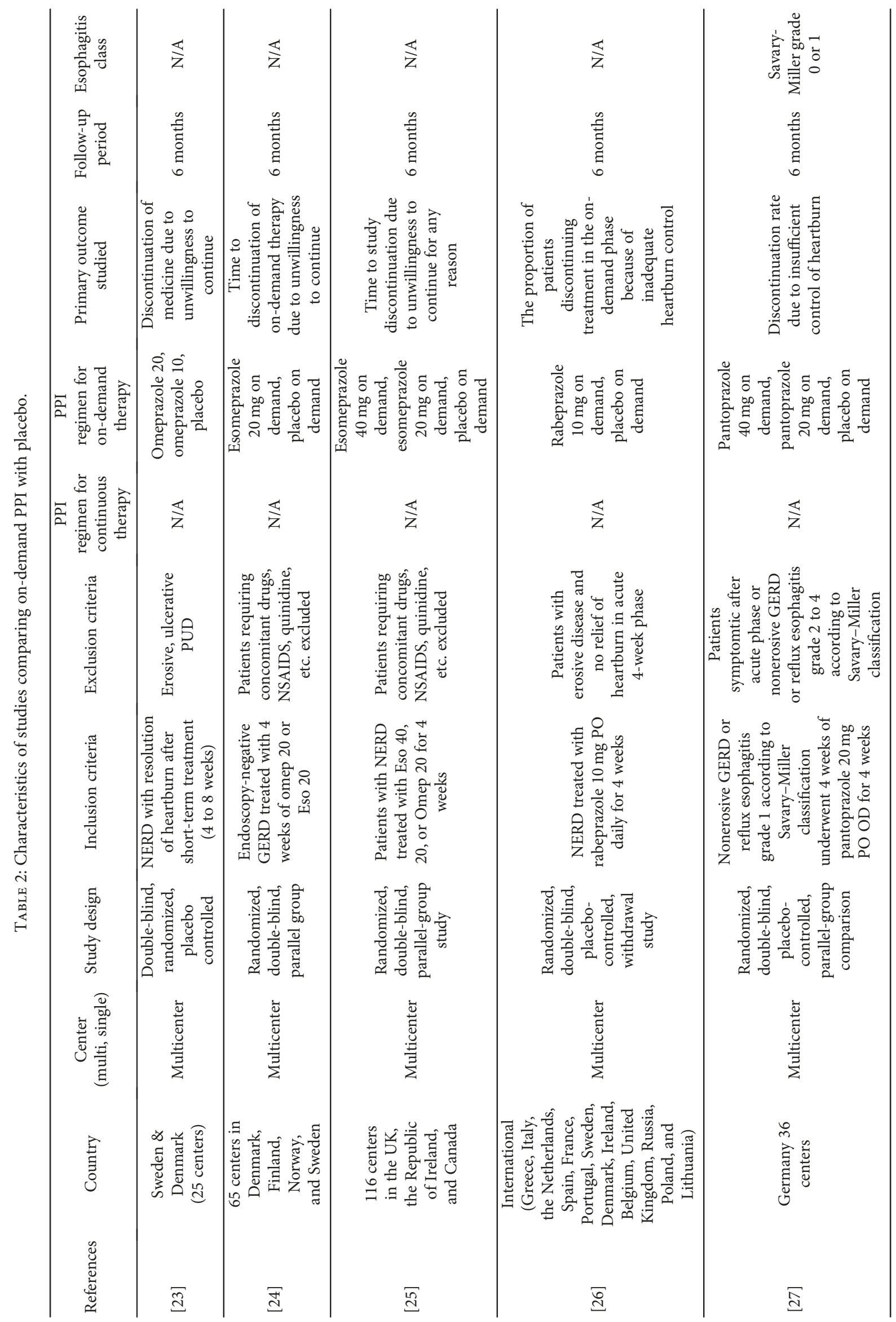




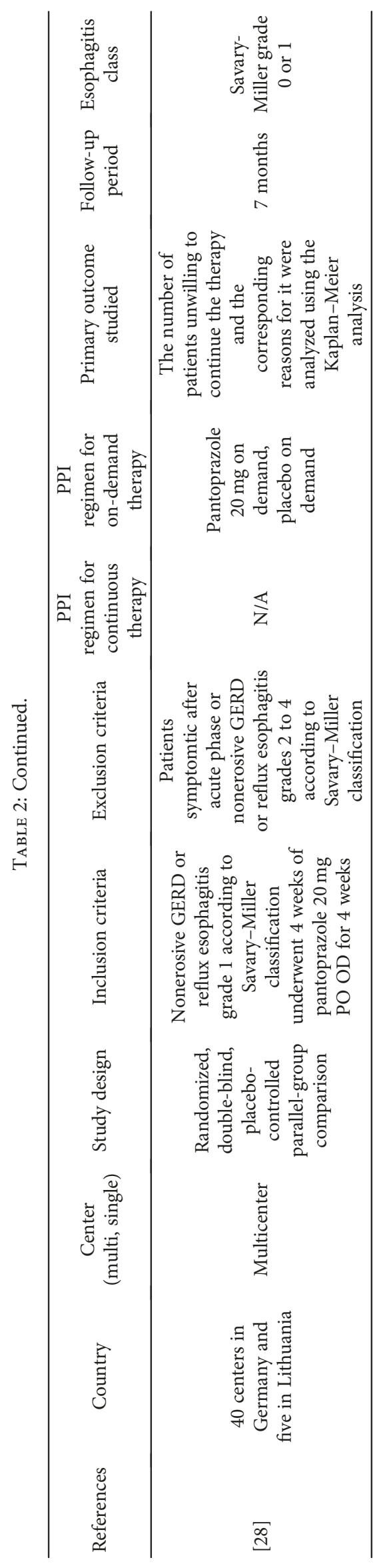


TABle 3: Patient characteristics and demographics of included trials.

\begin{tabular}{|c|c|c|c|}
\hline Study & $N$, on demand/cont & Mean age \pm SD & Male $(\%)$ \\
\hline \multirow{2}{*}{ Tsai et al. [19] } & (1) Eso $20 \mathrm{mg}$ on demand $=311$ & $51 \pm 13.8$ & $46 \%$ \\
\hline & (2) Lanso $15 \mathrm{mg}$ continuous $=311$ & $51 \pm 13.8$ & $41.8 \%$ \\
\hline \multirow{2}{*}{ Nagahara et al. [20] } & Omeprazole $20 \mathrm{mg}$ continuous $=18$ & \multirow{2}{*}{$56.2 \pm 12.8$} & \multirow{2}{*}{$21 / 35=60 \%$} \\
\hline & Omeprazole $20 \mathrm{mg}$ on demand $=17$ & & \\
\hline \multirow{2}{*}{ Bayerdörffer et al. [21] } & (1) Eso $20 \mathrm{mg}$ on demand $=301$ & $48.2 \pm 13.6$ & $40.5 \%$ \\
\hline & (2) Eso $20 \mathrm{mg}$ continuous $=297$ & $47.6 \pm 15.1$ & $43.8 \%$ \\
\hline \multirow{2}{*}{ Janssen et al. [22] } & Pantoprazole $20 \mathrm{mg}$ on demand $=215$ & 50.4 (SD 13.6) & $46.5 \%$ \\
\hline & Pantoprazole $20 \mathrm{mg}$ continuous $=217$ & $51.8(\mathrm{SD} 13.5)$ & $47.5 \%$ \\
\hline \multirow{3}{*}{ Lind et al. [23] } & (1) Omeprazole 20 on demand $=139(n)$ & $52(19-79) R$ & $38.1 \%$ \\
\hline & (2) Omeprazole 10 on demand $=142$ & $51(20-81) R$ & $45.8 \%$ \\
\hline & (3) Placebo $=143$ & $48(20-79) R$ & $42.7 \%$ \\
\hline \multirow{2}{*}{ Talley et al. [24] } & (1) Eso $20 \mathrm{mg}$ on demand $=170$ & $49(19-78) R$ & $55 \%$ \\
\hline & (2) Placebo on demand $=172$ & $49(21-79) R$ & $57 \%$ \\
\hline \multirow{3}{*}{ Talley et al. [25] } & (1) Esomeprazole $40 \mathrm{mg}$ on demand $=293$ & 48 & $46.1 \%$ \\
\hline & (2) Esomeprazole $20 \mathrm{mg}$ on demand $=282$ & 48.4 & $47.9 \%$ \\
\hline & (3) Placebo on demand $=146$ & 48.2 & $39.7 \%$ \\
\hline \multirow{2}{*}{ Bytzer et al. [26] } & (1) Rabeprazole $10 \mathrm{mg}$ on demand $=279$ & $47(0.81 \mathrm{SE})$ & $44 \%$ \\
\hline & (2) Placebo on demand $=139$ & $48(1.23 \mathrm{SE})$ & $41 \%$ \\
\hline \multirow{3}{*}{ Scholten et al. [27] } & Pantoprazole $40 \mathrm{mg}$ on demand $=218$ & $54 \pm 14$ & $47.3 \%$ \\
\hline & Pantoprazole $20 \mathrm{mg}$ on demand $=217$ & $52 \pm 14$ & $52.5 \%$ \\
\hline & Placebo on demand $=108$ & $52 \pm 14$ & $53.7 \%$ \\
\hline \multirow{2}{*}{ Kaspari et al. [28] } & Pantoprazole $20 \mathrm{mg}$ on demand $=213$ & $50.7 \pm 13.7$ years & $46 \%$ \\
\hline & Placebo on demand $=226$ & $51.0 \pm 14.5$ years & $43.3 \%$ \\
\hline
\end{tabular}

placebo. Four RCTs [19-22] compared a daily PPI regimen with on-demand treatment. Three of these were confined to patients with NERD [19-21], while the fourth [22] also included patients with mild EE. Six trials compared ondemand treatment with placebo [23-28]; four only included patients with NERD [23-26], and two included both patients with NERD or mild EE $[27,28]$. Tables $1-3$ highlight the characteristics of included studies.

\subsection{Meta-Analysis}

3.2.1. On Demand versus Daily PPI. For studies comparing on-demand PPI therapy with daily PPI therapy, 5.8\% of patients discontinued treatment in the on-demand group compared to $11.0 \%$ in the daily PPI group. The pooled OR with $95 \%$ confidence interval (CI) was $0.50(0.35,0.72)$, with no heterogeneity $\left(I^{2}=0 \%\right)$ (Figure 1$)$. On subgroup analysis of the three RCTs that included only NERD patients, results were similar; $5.7 \%$ of patients in the on-demand PPI group and $12.1 \%$ of patients in the daily PPI group discontinued treatment prematurely $(\mathrm{OR}=0.44 ; 95 \% \mathrm{CI}=0.29$ to 0.66$)$. However, on subgroup analysis of the study that included patients with either NERD or mild EE, there was no significant difference between treatments $(\mathrm{OR}=0.76 ; 95 \%$ $\mathrm{CI}=0.36$ to 1.60$)$. With on-demand treatment, $6.0 \%$ of patients discontinued treatment prematurely compared with $7.8 \%$ on daily PPI treatment.
3.2.2. On-Demand PPI Treatment versus Placebo. The proportions of patients prematurely discontinuing treatment were $11.6 \%$ with on-demand PPI therapy and $39.2 \%$ with placebo (pooled $\mathrm{OR}=0.21 ; 95 \% \mathrm{CI}=0.15$ to 0.29 ). There was significant heterogeneity among studies $\left(I^{2}=66 \%\right)$ (Figure 2 ). On subgroup analysis of studies conducted only in NERD patients, on-demand PPI treatment was superior to placebo; proportions of patients prematurely discontinuing treatment were $12.3 \%$ and $39.8 \%$, respectively $(\mathrm{OR}=0.22 ; 95 \% \mathrm{CI}=0.13$ to 0.36$)$. Among studies evaluating patients with either NERD or mild EE, proportions of patients discontinuing treatment prematurely were $10.2 \%$ and $38.0 \% \quad(\mathrm{OR}=0.18 ; 95 \%$ $\mathrm{CI}=0.11$ to 0.31 ), respectively.

\section{Discussion}

We found that on-demand PPI therapy was superior to both placebo and daily PPI therapy as maintenance treatment for patients with NERD or mild EE. In general, more patients were willing to continue on-demand PPI treatment than either of the alternatives studied. Furthermore, adherence to treatment and patient satisfaction were higher with ondemand PPI treatment compared to continuous PPI treatment. On-demand treatment may help to improve overall patient satisfaction since patients may feel more in control of their treatment and can take a dose of PPI according to their perceived needs and symptoms [18]. However, the 
On demand Daily PPI Odds ratio Odds ratio

Study or subgroup Events Total Events Total Weight $\mathrm{M}-\mathrm{H}$, random, 95\% CI $\quad$ Year $\quad$ M-H, random, 95\% CI

\begin{tabular}{|c|c|c|c|c|c|c|}
\hline \multicolumn{7}{|l|}{ 1.4.1 NERD only } \\
\hline Tsai, 2004 & 19 & 311 & 41 & 311 & $41.1 \%$ & $0.43(0.24,0.76)$ \\
\hline Nagahara, 2014 & 4 & 17 & 6 & 18 & $6.0 \%$ & $0.62(0.14,2.73)$ \\
\hline Bayerdörffer, 2016 & 4 & 17 & 6 & 18 & $6.0 \%$ & $0.42(0.21,0.82)$ \\
\hline \multicolumn{2}{|l|}{ Subtotal (95\% CI) } & \multicolumn{2}{|l|}{629} & 626 & $76.3 \%$ & $0.44(0.290 .66)$ \\
\hline Total events & \multicolumn{2}{|l|}{36} & \multicolumn{4}{|l|}{76} \\
\hline \multicolumn{7}{|c|}{ Heterogeneity: $\mathrm{Tau}^{2}=0.00 ; \mathrm{Chi}^{2}=0.23, \mathrm{df}=2(P=0.89) ; I^{2}=0 \%$} \\
\hline \multicolumn{7}{|c|}{ Test for overall effect: $Z=3.89(P<0.0001)$} \\
\hline \multicolumn{7}{|c|}{ 1.4.2 NERD + mild esophagitis } \\
\hline Janssen, 2005 & 13 & 215 & 17 & 217 & $23.7 \%$ & $0.76(0.36,1.60)$ \\
\hline \multicolumn{2}{|l|}{ Subtotal $(95 \% \mathrm{CI})$} & \multicolumn{2}{|l|}{215} & 217 & $23.7 \%$ & $0.76(0.36,1.60)$ \\
\hline Total events & 13 & & 17 & & & \\
\hline \multicolumn{7}{|c|}{ Heterogeneity: not applicable } \\
\hline \multicolumn{7}{|c|}{ Test for overall effect: $Z=0.73(P=0.47)$} \\
\hline Total (955 CI) & \multicolumn{3}{|c|}{844} & 843 & $100.0 \%$ & $0.50(0.35,0.72)$ \\
\hline Total events & 49 & & 93 & & & \\
\hline \multicolumn{7}{|c|}{ Heterogeneity: $\mathrm{Tau}^{2}=0.00 ; \mathrm{Chi}^{2}=1.82, \mathrm{df}=2(P=0.61) ; I^{2}=0 \%$} \\
\hline \multicolumn{7}{|c|}{ Test for overall effect: $Z=3.76(P=0.0002)$} \\
\hline Test for subgroup d & CII & $\mathrm{Chi}^{2}$ & -0 & 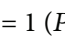 & .2 & . \\
\hline
\end{tabular}

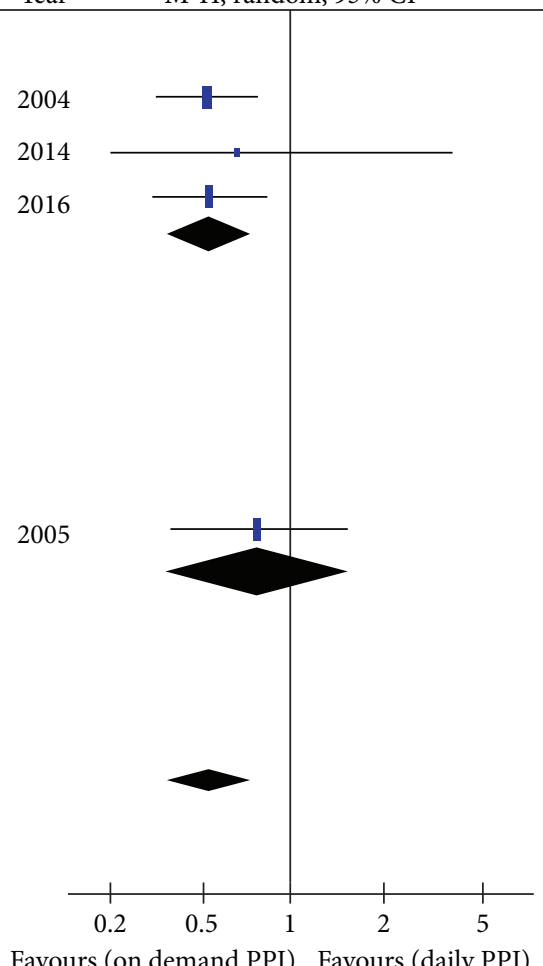

FIGURE 1: Forest plot comparing on-demand PPI with daily PPI.

usefulness of on-demand PPI treatment compared to daily PPI was less obvious when patients with mild EE were included in the analysis.

Our analysis is different from two previously conducted analyses. Jiang et al. [29] concluded that on-demand treatment with PPIs is superior to continuous or placebo therapy, but did not perform subgroup analysis of NERD and mild EE. A recently published Cochrane review showed that on-demand deprescribing may lead to an increase in gastrointestinal symptoms (e.g., dyspepsia and regurgitation) in patients with NERD or mild grades of EE (Los Angeles grades A and B or Savary-Miller grades 1 and 2) [30]. Besides having a broad definition for on-demand deprescribing, this review did not differentiate NERD from mild EE; Savary-Miller grading for most of the included patients was $>1$. In our analysis, the only included were patients with Savary-Miller grade 0 (NERD) or 1 (mild EE). We excluded studies that included EE patients with Savary-Miller grade higher than 1, since those would represent moderate and severe EE.

Since the risk of progression of NERD or mild EE to more advanced disease is low, symptom control is the main objective of management [31-33]. Many patients experience intermittent symptoms of short duration. These symptoms can be effectively managed with on-demand PPI treatment. This symptom-driven approach for the long-term management of NERD also simulates many patients' actual use of these medicines [16]. Many patients who are prescribed daily PPI treatment may actually consume them on an as needed basis. Up to $29 \%$ of patients who were prescribed continuous PPI treatment decreased the frequency of use without a recommendation from their providers, and only $21 \%$ of patients prescribed continuous PPI treatment fill their prescriptions in a manner to remain fully compliant with the recommended dosing schedule $[34,35]$. The most commonly cited reasons for not continuing treatment are inconvenience and cost. However, studies [36-38] evaluating the on-demand strategy versus continuous PPI treatment for EE have shown that the on-demand strategy is inferior. On-demand PPI treatment is, therefore, not appropriate or adequate for patients with EE of Savary-Miller grade 2 or above.

As well as patient preference and satisfaction for ondemand PPI treatment, cost of long-term treatment is also important. The consistently demonstrated efficacy and the favorable safety profile of PPI treatment have led to its widespread use in GERD patients [13]. There has been a substantial increase in the cost of GERD management with medicines contributing to overall costs. This has led to increasing concern from health care authorities and thirdparty payers [36]. On-demand PPI treatment might reduce overall consumption by up to one third. Tsai et al. [19], who compared on-demand esomeprazole with daily lansoprazole in 622 patients for six months, found that patients in the esomeprazole on-demand group took treatment on approximately one-third of the days ( 0.3 times per day) whereas 
On demand Daily PPI Odds ratio Odds ratio

Study or subgroup Events Total Events Total Weight M-H, random, 95\% CI Year $\quad$ M-H, random, 95\% CI

\begin{tabular}{|c|c|c|c|c|c|c|}
\hline \multicolumn{7}{|l|}{ 1.3.1 NERD only } \\
\hline Lind, 1999 & 66 & 281 & 63 & 143 & $18.4 \%$ & $0.39(0.25,0.60)$ \\
\hline Talley, 2001 & 24 & 170 & 87 & 172 & $16.2 \%$ & $0.16(0.09,0.27)$ \\
\hline Talley, 2002 & 55 & 575 & 61 & 146 & $18.4 \%$ & $0.15(0.10,0.2$ \\
\hline Bytzer, 2004 & 16 & 279 & 28 & 139 & $13.4 \%$ & $0.24(0.13,0.46)$ \\
\hline Subtotal $(95 \%$ CI $)$ & & 1305 & & 600 & $66.4 \%$ & $0.22(0.13,0.3$ \\
\hline Total events & 161 & & 239 & & & \\
\hline \multicolumn{7}{|c|}{ Heterogeneity: $\mathrm{Tau}^{2}=0.18 ; \mathrm{Chi}^{2}=11.58, \mathrm{df}=3(P=0.009) ; I^{2}=74 \%$} \\
\hline \multicolumn{7}{|c|}{ Test for overall effect: $Z=6.09(P<0.0001)$} \\
\hline \multicolumn{7}{|c|}{ 1.3.2 NERD + mild esophagitis } \\
\hline Scholten, 2005 & 41 & 435 & 46 & 108 & $16.8 \%$ & $0.14(0.09,0.23)$ \\
\hline Kaspari, 2005 & 25 & 213 & 81 & 226 & $16.8 \%$ & $0.24(0.14,0.3$ \\
\hline Subtotal $(95 \% \mathrm{CI})$ & & 648 & & 334 & $33.6 \%$ & $0.18(0.11,0.31)$ \\
\hline Total events & 66 & & 127 & & & \\
\hline \multicolumn{7}{|c|}{ Heterogeneity: $\mathrm{Tau}^{2}=0.08 ; \mathrm{Chi}^{2}=2.21, \mathrm{df}=1(P=0.14) ; I^{2}=55 \%$} \\
\hline \multicolumn{7}{|c|}{ Test for overall effect: $Z=6.36(P<0.00001)$} \\
\hline Total (955 CI) & & 1953 & & 934 & $100.0 \%$ & $0.21(0.15,0.2$ \\
\hline Total events & 227 & & 366 & & & \\
\hline \multicolumn{7}{|c|}{ Heterogeneity: $\mathrm{Tau}^{2}=0.12 ; \mathrm{Chi}^{2}=14.50, \mathrm{df}=5(P=0.01) ; I^{2}=66 \%$} \\
\hline \multicolumn{7}{|c|}{ Test for overall effect: $Z=8.97(P<0.00001)$} \\
\hline Test for subgroup & renc & $\mathrm{Chi}^{2}$ & 23 , & 1 & 0.63 & \\
\hline
\end{tabular}

FIGURE 2: Forest plot comparing on-demand PPI with placebo.

those receiving lansoprazole daily took treatment on approximately 4 of every 5 days ( 0.8 times per day) despite being instructed to take them every day. Bayerdörffer et al. [21] found similar results with mean daily drug consumption of 0.41 tablets in the on-demand group and 0.91 tablets in the continuous daily group. Therefore, on-demand treatment may be a cost-effective strategy for the long-term management of patients with NERD or mild EE. It can be effective in controlling symptoms and is convenient for, and acceptable to, many patients. Those patients with NERD or mild EE who do not obtain adequate relief with on-demand PPI treatment can be considered for regular, daily PPI treatment in the lowest effective dose.

The studies included in our analysis defined NERD based on symptoms and endoscopic findings without physiological demonstration of abnormal gastroesophageal reflux (acidic or weekly acidic), which could be a limitation. Also, most of the studies used only Savary-Miller grading for classifying esophagitis. The studies that classified esophagitis using the LA classification were very limited and did not differentiate between LA grades A and B. We tried to be conservative while defining mild esophagitis and so confined our analysis to studies with either LA grades $\mathrm{M}$ or $\mathrm{A}$ and considered LA grade $\mathrm{B}$ to be indicative of moderate-rather than mild-esophagitis.

\section{Conclusion}

On-demand PPI treatment appears to be effective for the long-term management of many patients with NERD or mild EE. After the initial control of symptoms with a course of PPI treatment, on-demand PPI treatment can be appropriately considered for the long-term management of such patients.
Abbreviations
PPIs: Proton pump inhibitors
GERD: Gastroesophageal reflux disease
EE: $\quad$ Erosive esophagitis
NERD: Nonerosive reflux disease
PRISMA: Preferred reporting items for systematic review and meta-analysis
RCT: $\quad$ Randomized clinical trial
OR: $\quad$ Odds ratio.

\section{Disclosure}

The abstract of this review was presented in the Digestive Disease Week 2017 held in Chicago. 


\section{Conflicts of Interest}

The authors declare that they have no conflicts of interest.

\section{Authors' Contributions}

Zubair Khan helped in the study design, data collection, statistical analysis, manuscript drafting, and final approval of the manuscript. Yaseen Alastal helped in the study design, data collection, statistical analysis, manuscript drafting, critical revision, and final approval of the manuscript. Muhammad Ali Khan helped in the development of search strategies, data collection, manuscript drafting, and final approval of the manuscript. Mohammad Saud Khan helped in the study design, manuscript drafting, and final approval of the manuscript. Basmah Khalil, Shreesh Shrestha, and Faisal Kamal helped in the data collection, manuscript drafting, and final approval of the manuscript. Ali Nawras helped in the manuscript drafting, critical revision for intellectual content, and final approval of the manuscript. Colin W. Howden helped in the statistical analysis, manuscript drafting, critical revision for intellectual content, and final approval of the manuscript.

\section{Supplementary Materials}

PRISMA flow chart for study selection. (Supplementary Materials)

\section{References}

[1] H. B. El-serag, "Time trends of gastroesophageal reflux disease: a systematic review," Clinical Gastroenterology and Hepatology, vol. 5, no. 1, pp. 17-26, 2007.

[2] L. Frank, L. Kleinman, D. Ganoczy et al., "Upper gastrointestinal symptoms in North America: prevalence and relationship to healthcare utilization and quality of life," Digestive Diseases and Sciences, vol. 45, no. 4, pp. 809-818, 2000.

[3] F. Pace and G. B. Porro, "Gastroesophageal reflux disease: a typical spectrum disease (a new conceptual framework is not needed)," The American Journal of Gastroenterology, vol. 99, no. 5, pp. 946-949, 2004.

[4] N. Vakil, S. V. van Zanten, P. Kahrilas, J. Dent, R. Jones, and the Global Consensus Group, "The Montreal definition and classification of gastroesophageal reflux disease: a global evidence-based consensus," American Journal of Gastroenterology, vol. 101, no. 8, pp. 1900-1920, 2006.

[5] H. B. El-Serag, "Epidemiology of non-erosive reflux disease," Digestion, vol. 78, no. 1, Supplement 1, pp. 6-10, 2008.

[6] J. C. Y. Wu, C. M. Y. Cheung, V. W. S. Wong, and J. J. Y. Sung, "Distinct clinical characteristics between patients with nonerosive reflux disease and those with reflux esophagitis," Clinical Gastroenterology and Hepatology, vol. 5, no. 6, pp. 690-695, 2007.

[7] M. Kulig, A. Leodolter, M. Vieth et al., "Quality of life in relation to symptoms in patients with gastro-oesophageal reflux disease- an analysis based on the ProGERD initiative," Alimentary Pharmacology \& Therapeutics, vol. 18, no. 8, pp. 767-776, 2003.

[8] P. Moayyedi and N. J. Talley, "Gastro-oesophageal reflux disease,” Lancet, vol. 367, no. 9528, pp. 2086-2100, 2006.
[9] B. van Pinxteren, K. E. Sigterman, P. Bonis, J. Lau, and M. E. Numans, "Short-term treatment with proton pump inhibitors, H2-receptor antagonists and prokinetics for gastrooesophageal reflux disease-like symptoms and endoscopy negative reflux disease," Cochrane Database of Systematic Reviews, no. 3, article CD002095, 2006.

[10] C. Donnellan, N. Sharma, C. Preston, and P. Moayyedi, "Medical treatments for the maintenance therapy of reflux oesophagitis and endoscopic negative reflux disease," Cochrane Database of Systematic Reviews, vol. 2, article CD003245, 2004.

[11] B. B. Dean, A. D. Gano Jr., K. Knight, J. J. Ofman, and R. Fass, "Effectiveness of proton pump inhibitors in nonerosive reflux disease," Clinical Gastroenterology and Hepatology, vol. 2, no. 8, pp. 656-664, 2004.

[12] Y. Kinoshita, K. Ashida, M. Hongo, and The Japan Rabeprazole Study Group for NERD, "Randomised clinical trial: a multicentre, double-blind, placebo-controlled study on the efficacy and safety of rabeprazole $5 \mathrm{mg}$ or $10 \mathrm{mg}$ once daily in patients with non-erosive reflux disease," Alimentary Pharmacology and Therapeutics, vol. 33, no. 2, pp. 213-224, 2011.

[13] J. J. Heidelbaugh, A. H. Kim, R. Chang, and P. C. Walker, "Overutilization of proton-pump inhibitors: what the clinician needs to know," Therapeutic Advances in Gastroenterology, vol. 5, no. 4, pp. 219-232, 2012.

[14] N. J. Shaheen, R. A. Hansen, D. R. Morgan et al., "The burden of gastrointestinal and liver diseases, 2006," The American Journal of Gastroenterology, vol. 101, no. 9, pp. 2128-2138, 2006.

[15] D. C. Metz, J. M. Inadomi, C. W. Howden, S. J. V. van Zanten, and P. Bytzer, "On-demand therapy for gastroesophageal reflux disease," The American Journal of Gastroenterology, vol. 102, no. 3, pp. 642-653, 2007.

[16] J. M. Inadomi, R. Jamal, G. H. Murata et al., "Step-down management of gastroesophageal reflux disease," Gastroenterology, vol. 121, no. 5, pp. 1095-1100, 2001.

[17] A. Liberati, D. G. Altman, J. Tetzlaff et al., "The PRISMA statement for reporting systematic reviews and meta-analyses of studies that evaluate healthcare interventions: explanation and elaboration," BMJ, vol. 339, no. jul21 1, article b2700, 2009.

[18] D. Atkins, D. Best, P. A. Briss et al., "Grading quality of evidence and strength of recommendations," BMJ, vol. 328, no. 7454, p. 1490, 2004.

[19] H. H. Tsai, R. Chapman, A. Shepherd et al., "Esomeprazole $20 \mathrm{mg}$ on-demand is more acceptable to patients than continuous lansoprazole $15 \mathrm{mg}$ in the long-term maintenance of endoscopy-negative gastro-oesophageal reflux patients: the COMMAND study," Alimentary Pharmacology \& Therapeutics, vol. 20, no. 6, pp. 657-665, 2004.

[20] A. Nagahara, M. Hojo, D. Asaoka, H. Sasaki, and S. Watanabe, "A randomized prospective study comparing the efficacy of on-demand therapy versus continuous therapy for 6 months for long-term maintenance with omeprazole $20 \mathrm{mg}$ in patients with gastroesophageal reflux disease in Japan," Scandinavian Journal of Gastroenterology, vol. 49, no. 4, pp. 409-417, 2014.

[21] E. Bayerdörffer, M.-A. Bigard, W. Weiss et al., "Randomized, multicenter study: on-demand versus continuous maintenance treatment with esomeprazole in patients with non-erosive gastroesophageal reflux disease," BMC Gastroenterology, vol. 16, no. 1, p. 48, 2016.

[22] W. Janssen, E. Meier, G. Gatz, and B. Pfaffenberger, "Effects of pantoprazole $20 \mathrm{mg}$ in mildgastroesophageal reflux disease: 
once-daily treatment in the acute phase, and comparison of on-demand versus continuous treatment in the long term," Current Therapeutic Research, Clinical and Experimental, vol. 66, no. 4, pp. 345-363, 2005.

[23] T. Lind, T. Havelund, L. Lundell et al., "On demand therapy with omeprazole for the long-term management of patients with heartburn without oesophagitis-a placebo-controlled randomized trial," Alimentary Pharmacology \& Therapeutics, vol. 13, no. 7, pp. 907-914, 1999.

[24] N. J. Talley, K. Lauritsen, H. Tunturi-Hihnala et al., "Esomeprazole $20 \mathrm{mg}$ maintains symptom control in endoscopynegative gastro-oesophageal reflux disease: a controlled trial of 'on-demand' therapy for 6 months," Alimentary Pharmacology \& Therapeutics, vol. 15, no. 3, pp. 347-354, 2001.

[25] N. J. Talley, T. L. Venables, J. R. B. Green et al., "Esomeprazole $40 \mathrm{mg}$ and $20 \mathrm{mg}$ is efficacious in the long-term management of patients with endoscopy-negative gastro-oesophageal reflux disease: a placebo-controlled trial of on-demand therapy for 6 months," European Journal of Gastroenterology \& Hepatology, vol. 14, no. 8, pp. 857-863, 2002.

[26] P. Bytzer, A. Blum, D. de Herdt, D. Dubois, and the trial investigators, "Six-month trial of on-demand rabeprazole $10 \mathrm{mg}$ maintains symptom relief in patients with non-erosive reflux disease," Alimentary Pharmacology and Therapeutics, vol. 20, no. 2, pp. 181-188, 2004.

[27] T. Scholten, C. P. M. Dekkers, K. Schütze, T. Körner, M. Bohuschke, and G. Gatz, "On-demand therapy with pantoprazole $20 \mathrm{mg}$ as effective long-term management of reflux disease in patients with mild GERD: the ORION trial," Digestion, vol. 72, no. 2-3, pp. 76-85, 2005.

[28] S. Kaspari, L. Kupcinskas, H. Heinze, and P. Berghöfer, "Pantoprazole $20 \mathrm{mg}$ on demand is effective in the long-term management of patients with mild gastro-oesophageal reflux disease," European Journal of Gastroenterology \& Hepatology, vol. 17, no. 9, pp. 935-941, 2005.

[29] Y. X. Jiang, Y. Chen, X. Kong, Y. L. Tong, and S. C. Xu, "Maintenance treatment of mild gastroesophageal reflux disease with proton pump inhibitors taken on-demand: a meta-analysis," Hepato-Gastroenterology, vol. 60, no. 125, pp. 1077-1082, 2013.

[30] T. A. Boghossian, F. J. Rashid, W. Thompson et al., "Deprescribing versus continuation of chronic proton pump inhibitor use in adults," Cochrane Database of Systematic Reviews, vol. 3 , article CD011969, 2017.

[31] N. Manabe, M. Yoshihara, A. Sasaki, S. Tanaka, K. Haruma, and K. Chayama, "Clinical characteristics and natural history of patients with low-grade reflux esophagitis," Journal of Gastroenterology and Hepatology, vol. 17, no. 9, pp. 949-954, 2002.

[32] J. Labenz, M. Nocon, T. Lind et al., "Prospective follow-up data from the ProGERD study suggest that GERD is not a categorial disease," The American Journal of Gastroenterology, vol. 101, no. 11, pp. 2457-2462, 2006.

[33] M. Fullard, J. Y. Kang, P. Neild, A. Poullis, and J. D. Maxwell, "Systematic review: does gastro-oesophageal reflux disease progress?," Alimentary Pharmacology \& Therapeutics, vol. 24, no. 1, pp. 33-45, 2006.

[34] A. P. Hungin, G. Rubin, and H. O'Flanagan, "Factors influencing compliance in long-term proton pump inhibitor therapy in general practice," The British Journal of General Practice, vol. 49, no. 443, pp. 463-464, 1999.
[35] A. P. Hungin, G. P. Rubin, and H. O'Flanagan, "Long-term prescribing of proton pump inhibitors in general practice," The British Journal of General Practice, vol. 49, no. 443, pp. 451-453, 1999.

[36] F. Johnsson, B. Moum, M. Vilien, O. Grove, M. Simren, and M. Thoring, "On-demand treatment in patients with oesophagitis and reflux symptoms: comparison of lansoprazole and omeprazole," Scandinavian Journal of Gastroenterology, vol. 37, no. 6, pp. 642-647, 2009.

[37] S. Sjostedt, R. Befrits, A. Sylvan et al., "Daily treatment with esomeprazole is superior to that taken on-demand for maintenance of healed erosive oesophagitis," Alimentary Pharmacology \& Therapeutics, vol. 22, no. 3, pp. 183-191, 2005.

[38] F. Pace, M. Tonini, S. Pallotta, P. Molteni, and G. B. Porro, "Systematic review: maintenance treatment of gastrooesophageal reflux disease with proton pump inhibitors taken 'on-demand'," Alimentary Pharmacology \& Therapeutics, vol. 26, no. 2, pp. 195-204, 2007. 


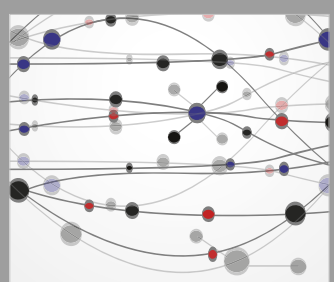

The Scientific World Journal
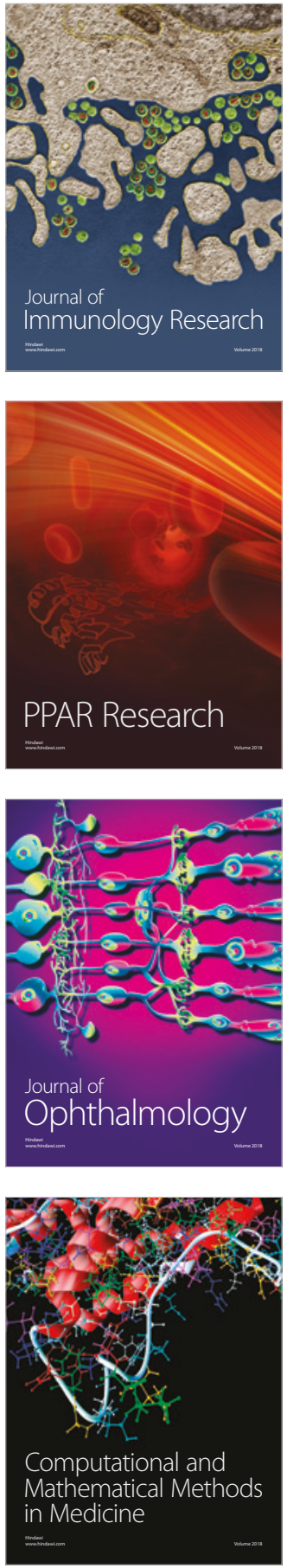

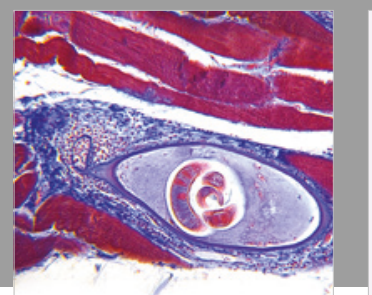

Gastroenterology Research and Practice

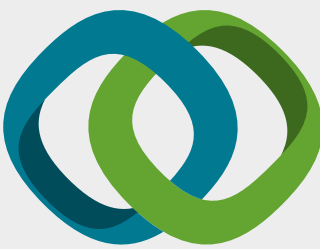

\section{Hindawi}

Submit your manuscripts at

www.hindawi.com
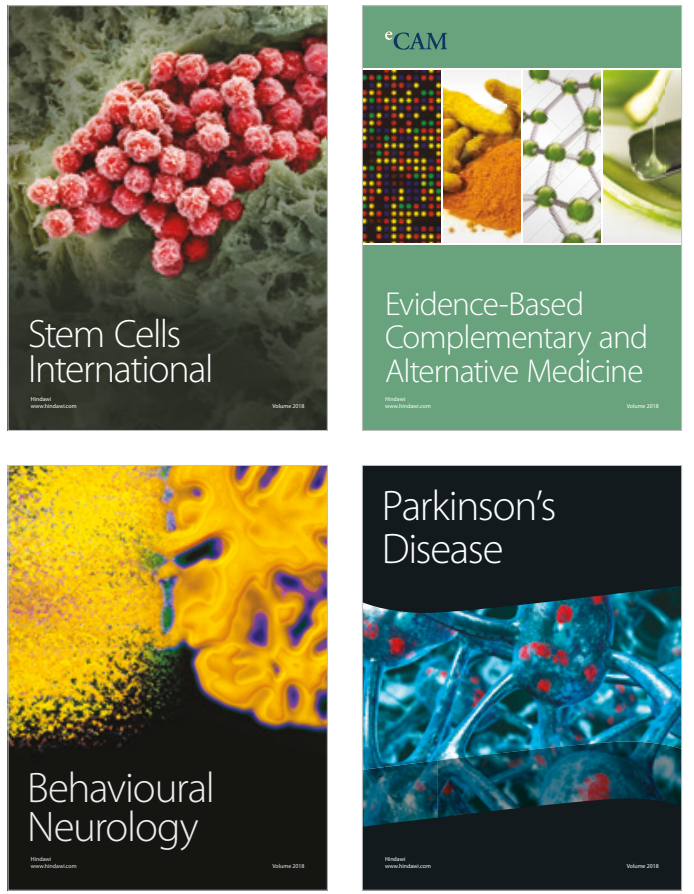

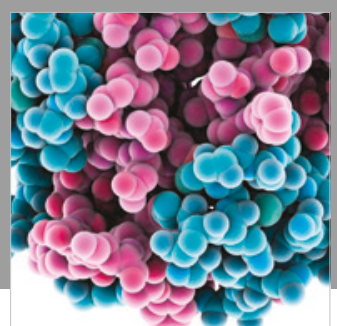

ournal of

Diabetes Research

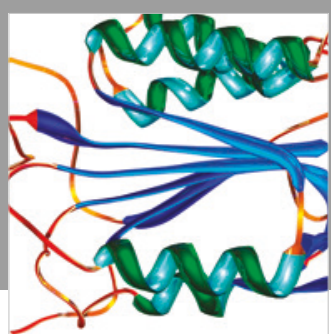

Disease Markers
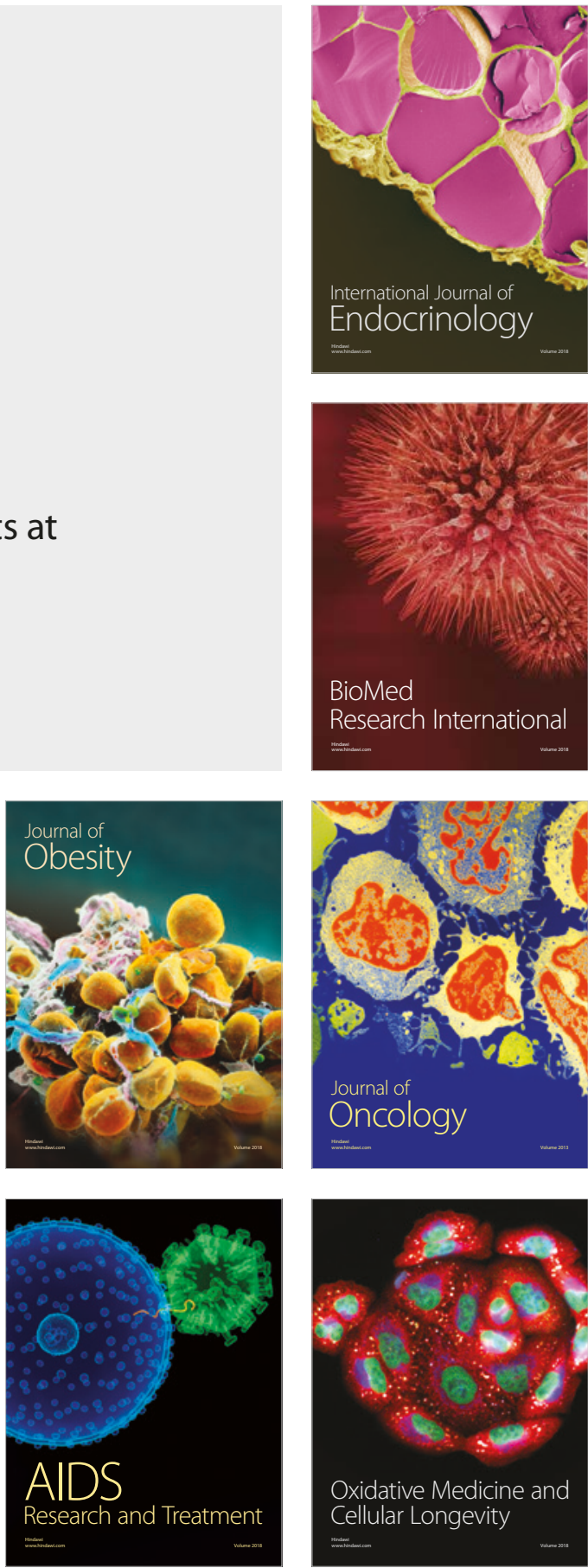